\title{
Damage from the Great East Japan Earthquake and Tsunami - A quick report
}

\author{
Nobuo Mimura • Kazuya Yasuhara • Seiki Kawagoe • \\ Hiromune Yokoki • So Kazama
}

Received: 4 May 2011 / Accepted: 6 May 2011 /

Published online: 21 May 2011

(C) The Author(s) 2011. This article is published with open access at Springerlink.com

\begin{abstract}
The Tohoku region, Northeast Japan, was hit by a gigantic earthquake which occurred in the Pacific close to Tohoku, and subsequently by a giant tsunami. These hazards have caused huge damage on the eastern coast Japan. The earthquake's magnitude was 9.0, the strongest ever recorded in Japan. The tsunami was also historical as its run-up height reached over $39 \mathrm{~m}$. As of early May, 2011, over 24 thousand people were reported as dead or missing. Moreover, serious accidents at the Fukushima Nuclear Power Plants No.1 were caused by the effects of the tsunami. Therefore, the damage faced by Japanese people can be seen as a giant composite disaster. Although Japan, and the northeast of Japan in particular, has over a long time period increased its preparedness against earthquakes and tsunamis, huge damage still occurred. This paper considers why this tragedy occurred, and what unrecognized factors contributed to the high vulnerability of the area. To assist in answering such questions, this paper presents a timely report of the features of the earthquake and tsunami, the damage they caused, and the early efforts for recovery and reconstruction.
\end{abstract}

Keywords Great East Japan Earthquake and Tsunami · Damage · Tsunami prevention measures $\cdot$ Nuclear power plant accident $\cdot$ Recovery and reconstruction

\footnotetext{
N. Mimura $(\bowtie) \cdot K$. Yasuhara

Institute for Global Change Adaption Science (ICAS), Ibaraki University, Mito, Japan e-mail: mimura@mx.ibaraki.ac.jp

S. Kawagoe

Faculty of Symbiotic Systems Science, Fukushima University, Fukushima, Japan

H. Yokoki

School of Engineering, Ibaraki University, Hitachi, Japan

S. Kazama

School of Engineering, Tohoku University, Sendai, Japan
} 


\section{Introduction}

At 2:46PM Japan Standard Time (JST) on 11th March, 2011, a gigantic earthquake occurred in the Pacific, just off the coast of Tohoku, Japan. The combined earthquake and resulting giant tsunami caused huge damage in eastern Japan. The earthquake's magnitude was 9.0, the maximum ever recorded in Japan. The tsunami was also historical in terms of its height and area affected. Its run-up height reached over $39 \mathrm{~m}$. As of early May, 2011, over 24 thousand people were reported as dead or missing. The number of temporary refugees exceeded 350 thousand at one time. Moreover, serious accidents at the Fukushima Nuclear Power Plants (NPP) No.1 of Tokyo Electric Power Co. (TEPCO) were caused by the tsunami. Figure 1 shows the locations of prefectures and places damaged heavily in the east Japan, which will be referred in this paper.

Japan has been long and repeatedly suffered from earthquakes and tsunamis. As $70 \%$ of its national land is occupied by mountainous areas, population, assets, industrial activities and infrastructure are concentrated in the narrow low-lying coastal areas. Japan has also made a long effort to prevent damage from natural hazards such as earthquakes and tsunamis. Significantly, the Tohoku coast which was heavily damaged by the March 11 event had developed the most advanced anti-earthquake/tsunami system in the world. So why did this tragedy happen? What factors contributed to the high vulnerability of the area?
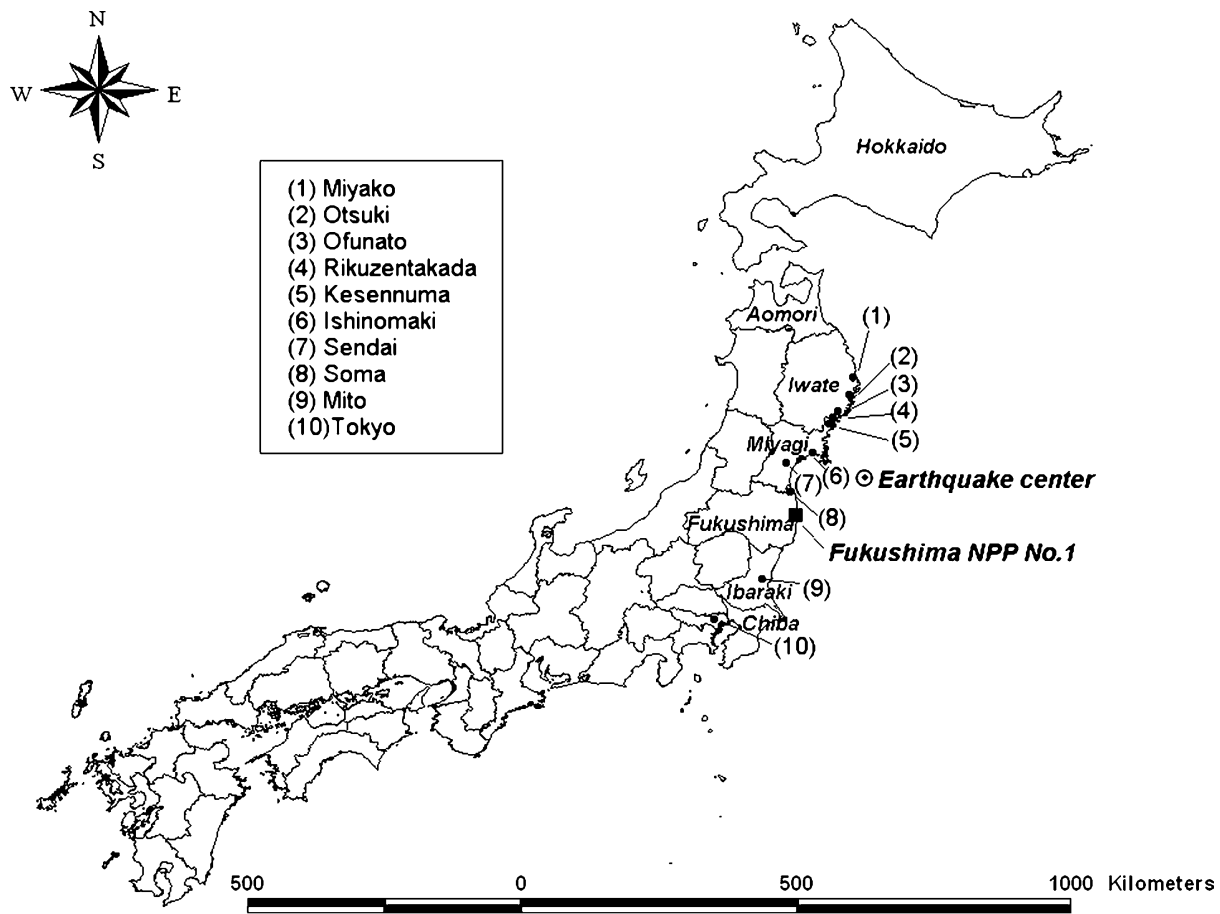

Fig. 1 Damaged prefectures and cities in the east Japan 
We are concerned that it is too early to present a report as so many refugees still remain in evacuation centers and we have only an incomplete picture of the disaster. However, Dr Robert Dixon, Editor of Mitigation and Adaptation Strategies for Global Change, invited us to prepare a paper as many people in the world wait for information from Japan. To respond to his request, we wrote this paper, as an interim report from university researchers in the affected area. As academic results are still limited, we used reports released by the government, research institutes and mass media as a basis of this paper.

The Japan Meteological Agency (JMA) named the earthquake as the "2011 off the Pacific Coast of Tohoku Earthquake". On the other hand, the government refers to the complex disaster as the "Great East Japan Earthquake and Tsunami". We follow the latter in this paper.

\section{Characteristics and damaged of the earthquake}

\subsection{Characteristics of the earthquake motion}

The epicenter of the Great East Japan Earthquake was at $38 \mathrm{~N}$ and 142.9E, as indicated in Fig. 2 The depth was estimated to be $24 \mathrm{~km}$. This earthquake is considered to be a plateboundary thrust-faulting in subduction area with a reverse fault. The Headquarters for Earthquake Research Promotion (2011), the Ministry of Ministry of Education, Culture, Sports, Science \& Technology, reported that the fault area stretched $400 \mathrm{~km}$ and $200 \mathrm{~km}$ in the NS and EW directions, respectively. In this area, at least three large earthquakes occurred consecutively, with the maximum slide distance of the crust amounting to $24 \mathrm{~m}$. Immediately after the earthquake the magnitude was reported as M8.8, but it was later corrected to M9.0. These parameters prove that the earthquake was unprecedented in Japan. The prefectures nearest to the epicenter (Iwate, Miyagi and Fukushima) were the worst affected as well.

To classify the ground motion, JMA uses the Japan's intensity of ground motion, with 0 to 7 classes. The highest class 7 of was recorded in Kurihara-city, Miyagi prefecture. Figure 3 shows that strong ground motion (ranking 6 to 7 and shown in dark colors) occurred in a wide coastal area of the east Japan.

By comparing the past strong earthquakes, we can identify the characteristics of the Great East Japan Earthquake as follows:

i) The earthquake was the biggest measured earthquake in Japan. Maximum recorded acceleration of the ground motion reached 3000 gal $\left(30 \mathrm{~m} / \mathrm{s}^{2}\right)$ in Kurihara-city, Miyagi prefecture. In addition, shaking lasted for nearly $6 \mathrm{~min}$, which reflected the consecutive breaks of the faults over a wide area. Based on such observations, the earthquake is considered to be a $1 / 1000$ year event.

ii) Many large aftershocks followed the main event (Fig. 2). The number of those larger than M5 is over 420 as of 19th April. One of the largest, with M7.1, occurred on 7th April. Moreover, the JMA suggested that an earthquake which took place on 9th March might be a foreshock. These indicate that the phenomena were a series of large scale crustal motions which will last for a considerable period of time, with ongoing consequences.

iii) The dominant period of the main earthquake was 0.2 to $1.0 \mathrm{~s}$. This range is shorter than that of the 1995 Great Kobe Earthquake. This is a possible reason why the damage of buildings was less intensive compared to the previous case in Kobe. 


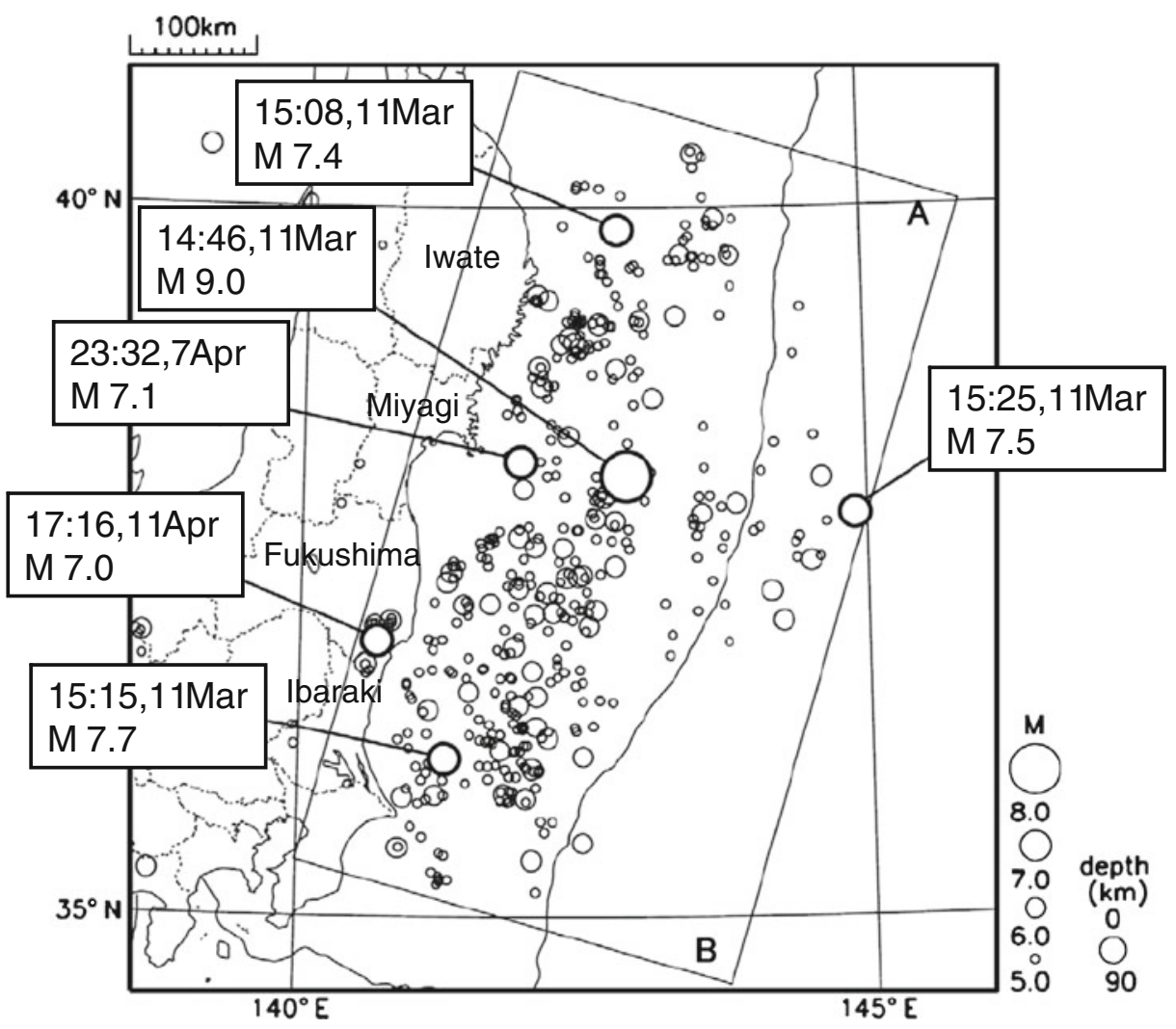

Fig. 2 Distribution of epicenters of the main earthquake and aftershocks (Revised from Japan Meteological Agency 2011a)

iv) Accidents of Fukushima NPP No.1 were induced. This makes the disaster much more serious to society, and the recovery pathways very complicated.

\subsection{Damage from the earthquake}

The earthquake resulted in huge damage. The Disaster Countermeasures Office (2011a), Office of Prime Minister, reported the following data on the damage as of 27th April.

i) Human casualties include 14,508 dead and 11,452 missing people. Since many areas are still left uninvestigated, the number is expected to increase.

ii) The number of completely collapsed and washed-out houses amounts to 76,000, and the number of those with half and partial damage is over 244,000. Following the earthquake, 345 fires occurred in 12 prefectures, including cases where the tsunami triggered the fire.

iii) Infrastructure damage was also very wide spread; reported damaged included 3,546 areas along roads, 71 bridges and 26 parts of the railway system. Such damage has strong effects on the recovery as well as on economic activities in general. On the other hand, thanks to the long efforts for disaster preparedness, the hundreds of trains 


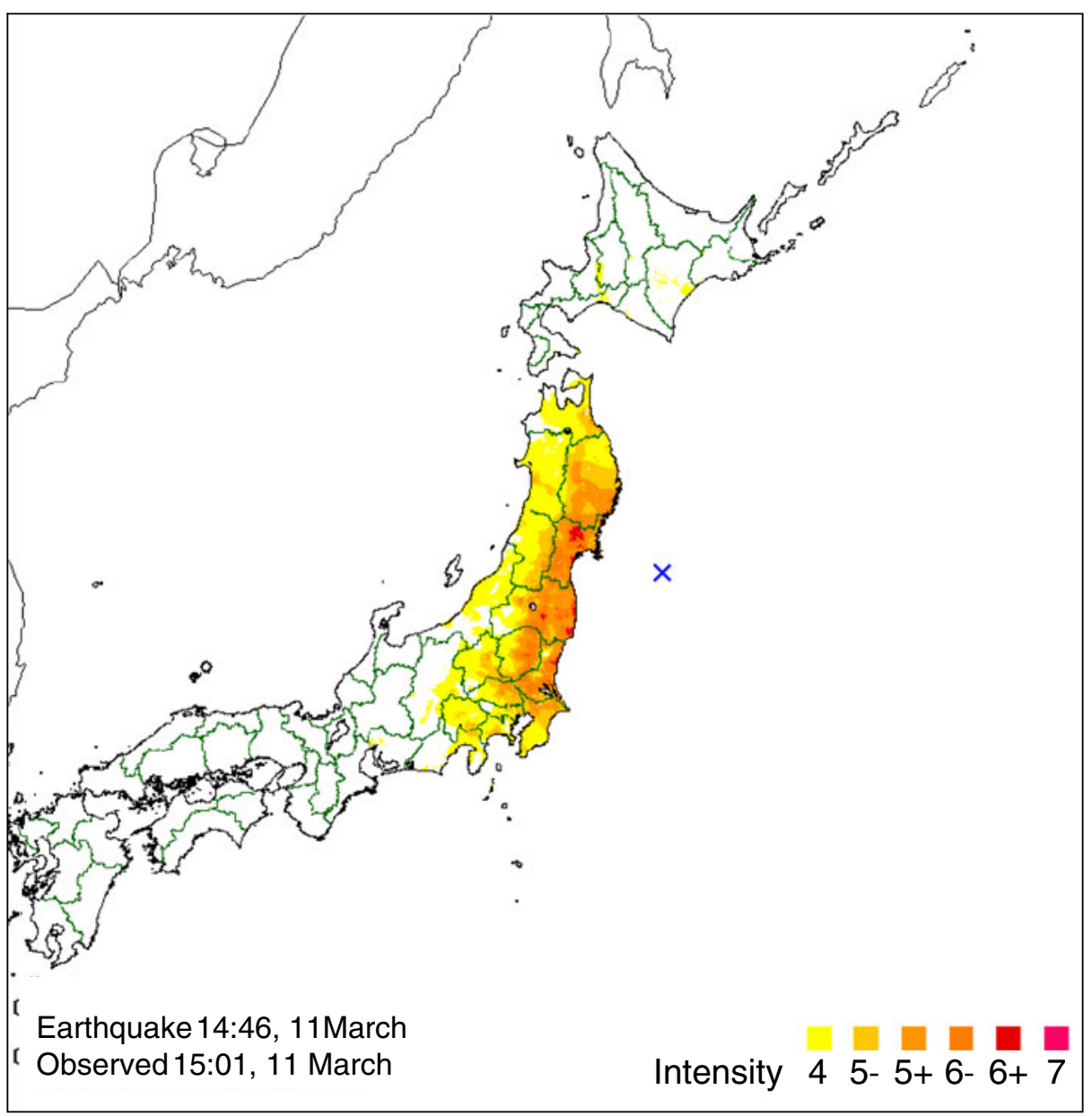

Fig. 3 Distribution of Japan's intensity of ground motion (Revised from Japan Meteological Agency 2011b)

in operation, including Tohoku Shin-Kansen, were able to make emergency stops safely, without any deaths or serious injuries.

iv) Lifeline infrastructure such as electricity, water supply, sewage systems, and gas lines, was also damaged. Though such services were soon restored in most of the damaged areas, the coastal areas most heavily damaged in the northeast Japan are still without these services at the time of writing.

v) The damage costs will be between 16 and 25 trillion yen.

According to the Geographical Survey Institute (2011), the main earthquake which occurred on the 11th March was associated with large movement of the crustal plate; i.e. about 4.0 to $5.0 \mathrm{~m}$ horizontal offshore movement and 0.4 to over $1.0 \mathrm{~m}$ subsidence. On land, large movements were also observed. The largest movement was at the Ojika Peninsula, Miyagi Prefecture, where $5.4 \mathrm{~m}$ (horizontal) and $1.20 \mathrm{~m}$ (vertical) movements of the ground were observed. 
As a result of such motions, many impacts occurred on artificially reclaimed lands, soft alluvial plains, and fragile slopes. These are common land features in Japan. Land slides also created strong damage, because the sediment mass has large weight, and hence apply stronger impulse forces to buildings and other features. For example, in Sukagawa-city, Fukushima Prefecture, a $18.1 \mathrm{~m}$ high earth dam was broken, causing eight deaths and missing people (Fig. 4). Another landslide and debris flow occurred in Shirakawa-city and Nasukarasuyama-city killing 13 people, and with two people still missing.

Building damage is closely related to the frequency responses. The frequency of the ground motion is higher than that of 1995 Great Kobe Earthquake, as shown in Fig. 5. This results in smaller effects on the structure of buildings. Therefore, the destroyed houses and buildings in the coastal areas were mainly due to the tsunami. However, in Ibaraki Prefecture, at the southern end of the damaged region, there were completely or half collapsed houses in inland areas. They were not damaged by the tsunami, but by the earthquake and resulting foundation failure.

Breakdown of lifelines continued for several weeks in many places. Figure 6 shows the recovery of water supply in Fukushima Prefecture as of 28th March. Much longer time is needed in the areas with tsunami damage and soft foundations. Damage to roads, railways and lifelines first resulted in insufficient supplies of food and gasoline to the impacted areas. Secondary effects then resulted, including on the physical and psychological conditions of refugees. These also became big problems for rescue activities.

The largest consequence of the earthquake and tsunami is the accident at the Fukushima NPP No1. Many serious problems have resulted, including nuclear contamination of soils and sea water, and evacuation of a large number of residents in

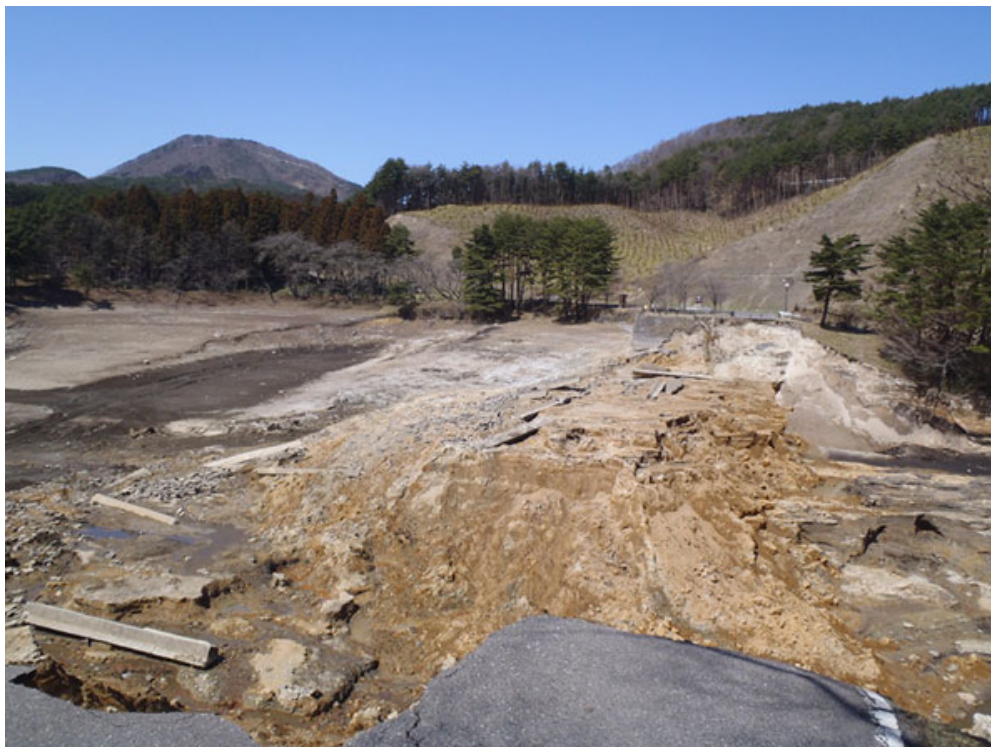

Fig. 4 Burst dam (Fujinuma reservoir) 
Fig. 5 Frequency characteristics of velocity response spectrum (Revised from Earthquake Research Institute (2011))

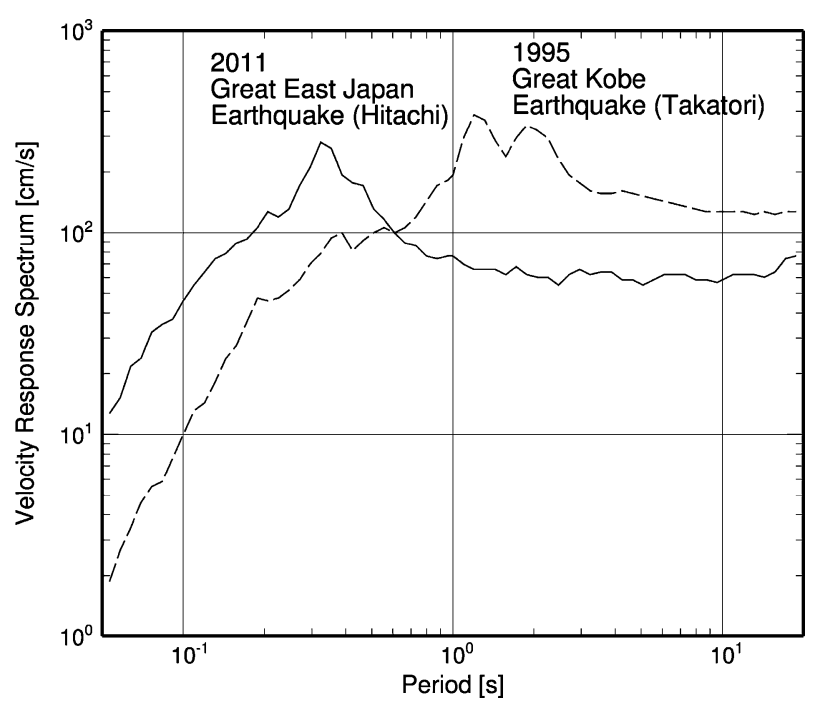

the surrounding areas, initially $20 \mathrm{~km}$ and then subsequently more distant from the NPP. This event revealed problems associated with risk management, and information disclosure as well. When the physical impacts of the earthquake and tsunami were combined with health, psychological, and social problems caused by the Fukushima NPP accident, the situation became very serious and complicated. The causes of the nuclear accident and the present situation at the NPP will be discussed later in this paper.

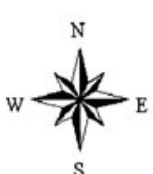

S

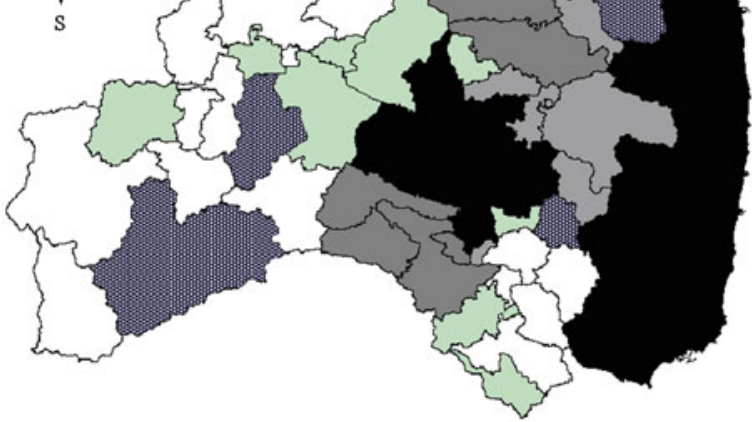

50

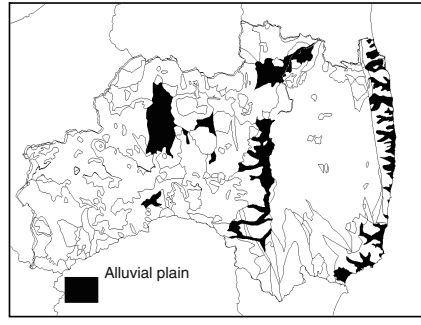

Alluvial plain map, Fukushima

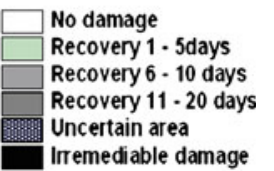

150 Kilometers

Fig. 6 Aqueduct damage map, Fukushima prefecture 


\section{Characteristics of the tsunami and its damages}

According to the tsunami-related information released by Japan Weather Association (2011), very soon after the major earthquake occurred at 2:46PM JST the first wave arrived at cities near to the failure fault, such as Miyako, Ofunato, and Kamaishi in Iwate Prefecture. The highest wave arrived at these locations between 3:15 and 3:20PM. This means that the highest waves reached the nearest coastlines 30 to $40 \mathrm{~min}$ after the earthquake occurred. The first waves arrived at more distant coasts, from Hokkaido in the north to Chiba Prefecture in the south, considerably later.

Very large wave heights occurred along southern Aomori, Iwate, Miyagi and northern Fukushima Prefectures. Wave heights and run-up elevations of tsunami are not the same; wave height is the distance between the mean sea level and the crest of the tsunami wave in the sea, while run-up elevation refers to the maximum height of the land where the tsunami reaches. Many tidal stations recorded high water levels of around $8 \mathrm{~m}$ in these areas, before they were destroyed by the tsunami, and no data were recorded. One exception is Onagawa NPP of Tohoku Electric Power Co. It recorded temporal variations of sea surface elevation at the coast, as shown in Fig. 7. This is a precious record obtained at a central position in the severely damaged region. This record shows that a large wave of nearly $13 \mathrm{~m}$ high arrived just before 3:30PM, with lowest values occurring around 15:45. More data are expected to be published from sensors in the deep sea floor.

Ria coasts dominate in the damaged area in Iwate Prefecture. The coasts consist of many bays and rocky cliffs. People concentrate in narrow flat plains along the bays, to form cities such as Rikuzen-Takata and Miyako, and fishery and/or commercial ports such as Kamaishi and Ofunato. These names of these cities will be used when describing more local damage. The tsunami hit these bays with a wave height of over $10 \mathrm{~m}$, the height being higher due to the amplification effect of the horn aperture of the bays. Table 1 indicates a summary of the strength of the tsunami and inundation, and the resulting human casualties for several cities in this area. For example, in Rikuzen-Takata-city, the wave height was over $15 \mathrm{~m}$, with the highest run-up elevation being about $39 \mathrm{~m}$. Furthermore, tsunami waves extended up along a river and flooded over river dikes in the middle and upper reaches. There are some areas which were hit by both tsunamis approaching from the coast and rivers, in a pincer attack. As these places are several kilometers inland from the coast, people did not expect that such flooding would occur. The overwhelming force of tsunami inundated $43 \%$ of the residential areas, and caused 2,422 deaths and missing people, accounting for $10.4 \%$ of the total city population.

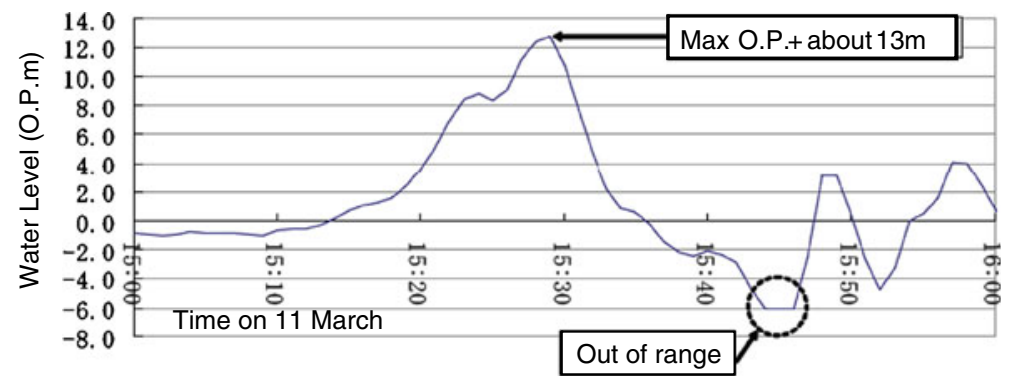

Fig. 7 Tsunami wave profile observed at Onagawa coast, Miyagi Prefecture. Note: O.P. is the datum at Onahama Port, Fukushima Prefecture. (Revised from Tohoku Electric Power Co. (2011)) 
Table 1 Examples for height and areas of inundation due to the tsunami, and the resulting damage (Summarized from Japan Weather Association (2011) and Disaster Countermeasures Office (2011a))

\begin{tabular}{lcccccc}
\hline Places & $\begin{array}{l}\text { Inundation } \\
\text { height }(\mathrm{m})\end{array}$ & $\begin{array}{l}\text { Inundation } \\
\text { Ares }(\mathrm{km} 2)\end{array}$ & $\begin{array}{l}\text { Rate of } \\
\text { inundation } \\
\text { area }(\%)\end{array}$ & $\begin{array}{l}\text { Rate of inundated } \\
\text { residential area }(\%)\end{array}$ & $\begin{array}{l}\text { Dead and } \\
\text { missing } \\
\text { people }\end{array}$ & $\begin{array}{l}\text { Rate of dead and } \\
\text { missing people } \\
(\%)\end{array}$ \\
\hline Rikuzen-Takata & 15.8 & 13 & 5.6 & 43 & 2,422 & 10.4 \\
Kamaishi & 9.3 & 7 & 1.6 & 22 & 1,310 & 3.3 \\
Otsuchi & 12.6 & 4 & 2.0 & 52 & 1,631 & 10.7 \\
Ishiniomaki & 15.5 & 73 & 13.1 & 46 & 5,538 & 3.5 \\
Onagawa & 14.8 & 3 & 4.5 & 48 & 1,504 & 15.0 \\
Minamisanriku & 15.9 & 10 & 6.1 & 52 & 1,095 & 6.3 \\
\hline
\end{tabular}

The $100 \mathrm{~km}$ stretch south of the Ria coasts has sandy coasts, stretching from Miyagi Prefecture to northern part of Fukushima Prefecture. The coastal plain is called Sendai Plain, as Sendai-City, the largest city in Tohoku Region, is situated inland on this plain. A wave height of $7 \mathrm{~m}$ was observed at Souma, the southern tip of this coast. The elevation of the plain is less than $5 \mathrm{~m}$, and high tsunami waves penetrated deep into it. The maximum penetration distance was about $6 \mathrm{~km}$. Flooding on such a wide area, and the resulting damages, are unprecedented.

Ibaraki and Chiba Prefectures are south of Fukushima Prefecture. Tsunamis of $3.3 \mathrm{~m}$ to $7.2 \mathrm{~m}$ high (Ibaraki) and $1.3 \mathrm{~m}$ to $7.6 \mathrm{~m}$ high (Chiba) were observed. Consequently, the tsunami associated with the Great East Japan Earthquake attached a long coastline of over $800 \mathrm{~km}$ in the northeast Japan, representing a major external force that imposed devastating damages on the coastal areas.

\section{Some aspects of the tsunami damage}

\subsection{Effects of coastal dykes and breakwaters}

The Pacific coast of northeast Japan is called Sanriku Region. This region has suffered from large tsunamis in the past: it experienced enormous damage in 1886 (Meiji Snriku Tsunami), 1933 (Showa Sanriku Tsunami), 1960 (Chilean Earthquake Tsunami) and 1968 (Off Tokachi Tsunami). Based on these disasters, the national and local governments continued to increase the level of the tsunami countermeasures. As one of such measures, large breakwaters were constructed at the mouths of Ofunato, Kamaishi, Miyako, and Kuji bays, to protect the cities located in the inner bay areas against tsunamis.

Among the tsunami protection facilities, giant bay-mouth breakwaters were noteworthy. For example, Kamaishi Bay has a breakwater consisting of north and south parts of $990 \mathrm{~m}$ and $670 \mathrm{~m}$ length, respectively, and a total length of $2 \mathrm{~km}$. Its maximum depth below water is $63 \mathrm{~m}$, while the height above mean sea level is $8 \mathrm{~m}$. Its design criterion was to protect the city and port of Kamaishi against the Meiji Sanriku Tsunami, which was caused by a M8.5 earthquake in 1896. About 6,700 people were killed and 1,600 houses were washed away by the tsunami. Therefore, constructing this breakwater has long been desired by the local people. This breakwater was completed in 2009, using 700 million $\mathrm{m}^{3}$ of concrete. This breakwater is registered in the Guinness Book of World Records as the deepest breakwater in the world. It played a role to protect the city against tsunamis, until March 11. Ofunato 
also has a big bay-mouth breakwater with a total length of $550 \mathrm{~m}$ and a depth of $40 \mathrm{~m}$. Though water pollution in the bay became worse after the breakwater was constructed, residents considered the tsunami protection to be more important relative to any adverse consequences.

Taro district, in Miyako City, was surrounded by high coastal dykes called "Great Walls". They were $10 \mathrm{~m}$ high and $10 \mathrm{~km}$ in total length (Fig. 8). Taro experienced a tragedy after being hit by a $10 \mathrm{~m}$ tsunami which killed over 900 people in 1933 . They started to build the coastal dykes the following year. In 1958 a $10 \mathrm{~m}$ dyke system with a length of $1.4 \mathrm{~km}$ was completed. It worked very well in the occasion of the Chilean Tsunami in 1960, with no casualties. In 1979 the dyke system was partially upgraded to a great wall with a two-track structure. After that it continued to be effective.

The recent Great East Japan Tsunami flew over these structures, attacking cities and causing huge casualties. The bay-mouth breakwaters were destroyed in Kamaishi and Ofunato. The great coastal dykes in Taro could not prevent overflows and were destroyed as well. Some people claimed that the structures had no effect, and that disaster prevention education should be more effective. However, evidence from videos, photos and witnesses confirms that the coastal structures reduced the damage to some extent. Thus the role of coastal structures remains a controversial issue. However, it is true that the structures played a preventive role against past tsunamis which had heights lower than their design heights. Therefore, the role and effectiveness of structures when the tsunami is higher than the design criterion is a matter for further study.

\subsection{Education for disaster prevention}

People of cities in northeast Japan, such as Kesennuma and Kamaishi, are enthusiastic about tsunami disaster prevention. They have been very effective in this regard, by

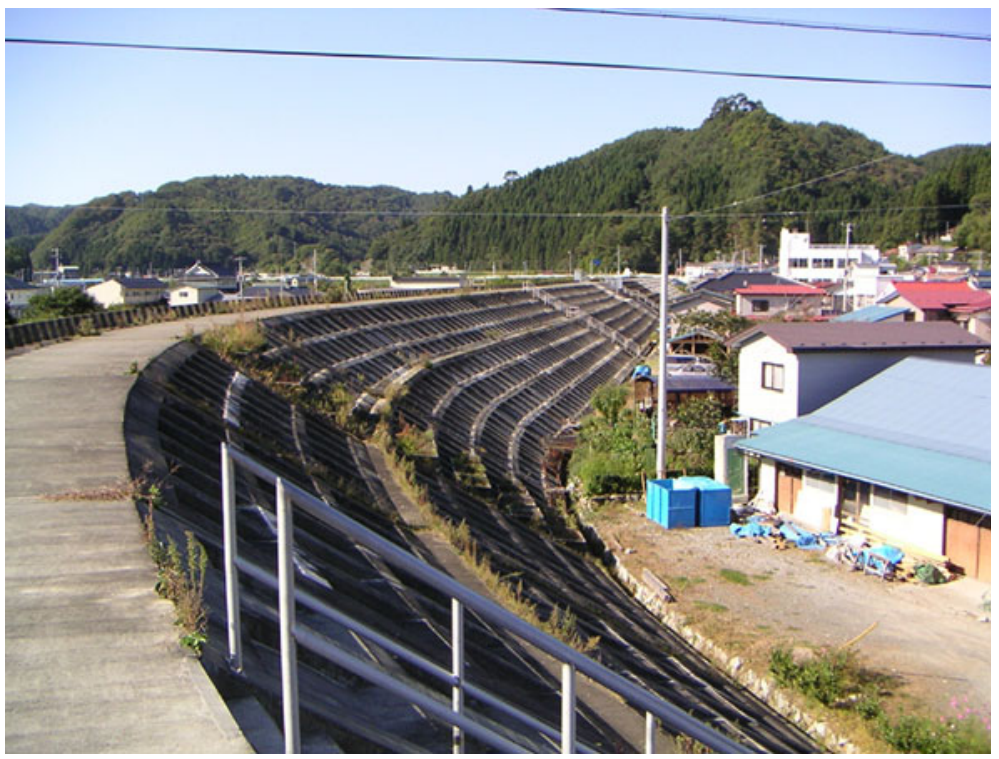

Fig. 8 Ten meter high coastal dykes in Taro, Miyako City (Before the tsunami; Ministry of Land, Infrastructure, Transport and Tourism) 
organizing workshops, education for tsunami disasters and evacuation practices over the past 20 years. In particular, after the construction of the breakwaters, they also strengthened soft measures such as distribution of tsunami hazard maps to all households. Each city/town government prepared a tsunami hazard map, which overlays the estimated inundation areas of tsunamis and river floods, as well as risk areas for slope failures, based on scientific estimates. Moreover, they also promoted soft measures in local workshops for disaster prevention, such as discussions and practices to find evacuation places and routes. Loud speakers and radio transmissions were installed in each city or town to announce emergency cautions.

These prevention activities had a great effect, even in face of the gigantic tsunami. Special note should be mentioned about the fact that nearly 3,000 children in elementary and middlehigh schools managed to evacuate safely in Kamaishi. There is a legend of "Tsunami tendenko". As "tendenko" means "scattered" in local language, the legend has been transferred for a long time to teach that, when you feel an earthquake, you should not wait for a unified action but run away individually and immediately. After the Great East Japan Earthquake, most elementary and middle-high schools evacuated students to higher places. Importantly, this action was taken before local authorities issued evacuation alerts. On the other hand, some people regretted that they relied too much on hard structures such as coastal dykes, based on the fact as they thought that these structures had successfully protected against tsunamis until then.

There was an instance where raised awareness was of no assistance. In Otsuchi, officers of the town government evacuated from the town hall after the earthquake. The tsunami attacked them shortly after they established a disaster countermeasure office outside of the town hall. Eleven officers, including the town mayor, were killed or missing, out of 14 staff in Otsuchi (Fig. 9). They thought that they were responsible to lead people's evacuation rather than their own evacuation. They also tried to achieve allocated emergency roles such as shut-down of water gates and preparation of evacuation centers. Their roles conflicted with their own "evacuation first".

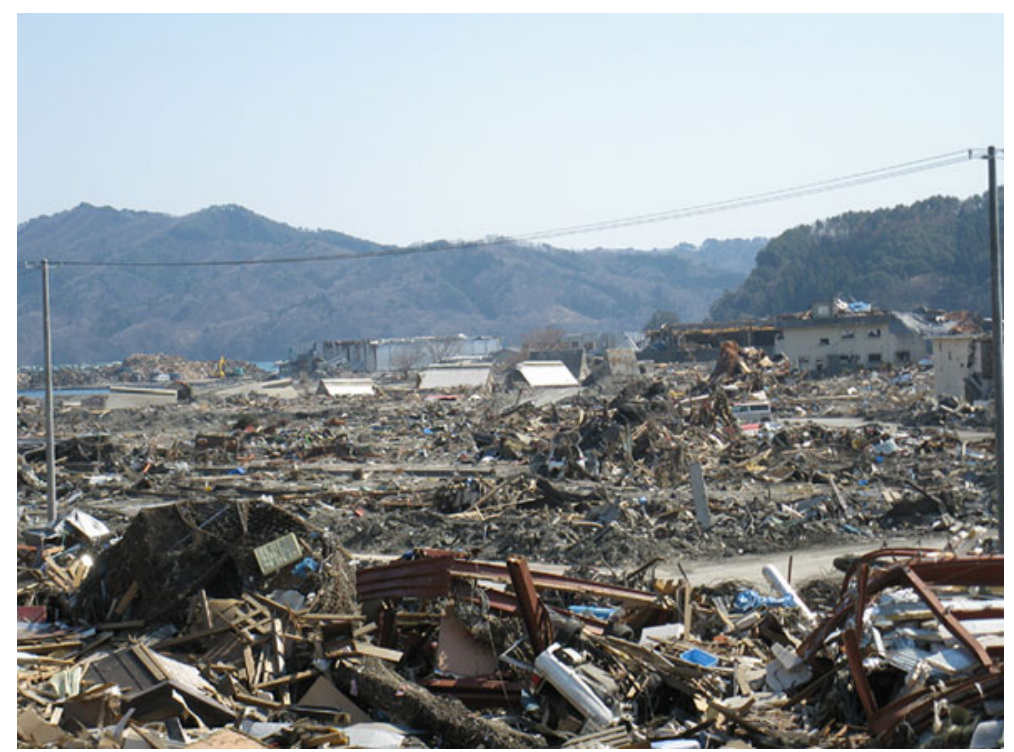

Fig. 9 Damages in Otsuchi (Photo: So Kazama, 5th April) 


\subsection{Aged victims}

According to a newspaper, the dead people over 60 and 70 years accounted for $65 \%$ and $45 \%$, respectively, of the 2,854 victims in five prefectures. There are $35 \%$ and $21 \%$ in these age-groups in Iwate Prefecture,. Thus the victims' rates are twice as large. This clearly indicates a disproportionately high death rate for aged people. In the case of the 1995 Great Kobe Earthquake, people over 70 years accounted for $40 \%$ of the deaths in Hyogo Prefecture. Higher mortality rates for aged people have been recognized as an important issue in the past, and was the same for the Great East Japan Earthquake and Tsunami. One reason is that people in hospitals and nursing-care facilities need a longer time for evacuation. Single people and aged people who need nursing-care are also less able to make a quick evacuation. Therefore, we need to develop evacuation measures that are effective for Japan's aged society.

\subsection{Recovery and reconstruction}

There are different challenges recovering from tsunami damages compared to those from earthquakes. The first challenge is the interruption to transportation in the coastal areas. Ports, railways and roads could not be used due to heavy damage. Some places could be accessed only by helicopter. In fact, air transportation was the only way to bring water, food and other life necessities to islands for 2 weeks.

Some municipalities lost city/town halls, and could not provide help and services to people. The most tragic town is Otsuchi where many officers were killed by the tsunami. It could not establish even the disaster countermeasures office. Other municipalities sent their officers to help them from a week later. As the officers themselves were victims of disasters to a greater or lesser degree, it is very hard to establish a headquarter office to help refugees and affected people. Many NPOs and local people worked to help them.

Another problem is safety management of rescue activities for aftershocks and possible further tsunamis. Data transmission stopped from many tsunami monitoring stations off the Pacific coast operated by JMA. For example, tsunami measurement station at Soma, Fukushima Prefecture, ceased data transmission after sending increasing water surface to $7.3 \mathrm{~m}$ at 3:50PM on March 11. Nine of ten tidal stations could not send their data after the first or second tsunami wave, or immediately after the earthquake. By then the region had lost its tsunami monitoring capability for a certain period of time.

Ground subsidence has increased the risk of inundation in a wide area along the Pacific coast. As mentioned in Section 2.2, subsidence ranges from 0.4 to $1.2 \mathrm{~m}$. Sea water piling up in the inundated area did not return to the sea naturally, and it was a large obstacle for investigation of missing people and for rescue activities. Although local authorities introduced many pumper trucks, drainage of sea water takes time because the inundated areas are very expansive. As a result of ground subsidence and collapse of seawalls after the earthquake, parts of the coastal areas were inundated by regular tidal motion during spring tide,. The Pacific coast of the northeast Japan faces a huge problem of how to reconstruct the protection system against high tide, waves, storm surges and tsunamis.

Disaster wreckage is another big problem. The earthquake and tsunami generated 25 million tons of wreckage in only the three prefectures of Iwate, Miyagi and Fukushima. It is not possible to take the wreckage to outer areas. Stock piling a mixture of wreckages may cause contamination of soils, sandy beaches, and surface and ground waters. Therefore, disasters and their recovery are closely connected to environmental problems. Disaster 
management plans focus on the refugees etc., but seldom consider the treatment of the wreckage. There is a need to incorporate this issue in disaster management plans.

\section{Tsunami and the accident at the Fukushima Nuclear Power Plant No.1}

The most serious consequence of the tsunami is the accident of Fukushima NPP No.1. Construction of the first nuclear reactor in Fukushima started in 1967, and six reactors were built over a period of about 10 years. Table 2 shows the year construction started and the generation capacity of each reactor. The generation capacity of the Fukushima No.1 was 4,696 MW in total, which amounts to $6 \%$ of the gross supply capacity of the TEPCO. Fukushima NPP No.2 is located $10 \mathrm{~km}$ south of Fukushima No.1. These two NPPs are all situated on the coast, with their own ports for transportation of nuclear fuels and cooling water uptake. The Fukushima coast, therefore, is Japan's big electricity supply base. The giant tsunami hit it, inducing the severe accident and raising serious concerns in Japan and, furthermore, around the world.

The events after the accident occurred are as follows, according to Disaster Countermeasures Office (2011b), Office of Prime Minister.

2:46PM, 11th March, the great earthquake occurred. Nuclear reactors 1 to 3 made emergency shut-downs successfully, while the other reactors 4 to 6 were not operating because of regular inspection. As the electric feeder lines to Fukushima NPP No.1 were damaged by the earthquake, emergency generators started to power the emergency cooling system. However, the first wave of the tsunami arrived at 3:27PM, and the second wave at 3:35PM, inundating the buildings housing the nuclear reactors and generators with water 4 to $5 \mathrm{~m}$ deep. As a consequence, the emergency generators stopped, and reactors 1 to 5 lost electricity for cooling systems.

After 12th March, cooling water levels were lowered in reactors 1 to 3, resulting in damage and partial melting of nuclear fuel rods. To protect the nuclear reactors, pressure was lowered by releasing water vapor out of the reactors. This diffused radioactive matter into the atmosphere. At the same time, as used nuclear fuel rods were stored in pools in the buildings, there was also a need to cool the pools continuously. As of the end of April, 2011, though the situation is becoming stable, unprecedented long-term efforts are necessary to stabilize the rectors.

Obviously, the tsunami triggered the accident. TEPCO (2011) recently reported that the tsunami run-up elevation was 14 to $15 \mathrm{~m}$, whereas the height of the design tsunami was $5.7 \mathrm{~m}$. The ground elevation of the Fukushima NPP No.1 is about $10 \mathrm{~m}$, and the emergency cooling pumps were set in the basements of the buildings. Therefore, the reactors lost the cooling system due to tsunami flooding.

Table 2 Basic Information of the Fukushima Nuclear Power Plant No.1

\begin{tabular}{llll}
\hline Power unit & Capacity (MW) & Construction start & Condition at the earthquake break \\
\hline Unit 1 & 460 & Sep. 1967 & Operation \\
Unit 2 & 784 & May 1969 & Operation \\
Unit 3 & 784 & Oct. 1970 & Operation \\
Unit 4 & 784 & Sep. 1972 & Regular inspection \\
Unit 5 & 784 & Dec. 1971 & Regular inspection \\
Unit 6 & 1100 & May 1973 & Regular inspection \\
\hline
\end{tabular}


There are other nuclear power plants located on the Pacific coast, such as Onagawa (Miyagi), Fukushima No.2, and Tokai No.2 (Ibaraki). These were also affected by the tsunami, but no critical accident occurred. This is mainly because in each case the elevation of the ground were high enough compared with the tsunami's run-up. For example, in Fukushima No.2, the run-up height was 6.5 to $7 \mathrm{~m}$, higher than the design height of $5.2 \mathrm{~m}$. However, the major buildings were situated on ground which is $12 \mathrm{~m} \mathrm{high}$. The damage from the tsunami was not large (TEPCO, 2011). Significantly, the Onagawa NPP of the Tohoku Electric Power Co. was hit by a $13 \mathrm{~m}$ tsunami, but, as the ground level was $13.8 \mathrm{~m}$, it only suffered from a small inundation (Tohoku Power Co. 2011).

As already mentioned, the Pacific coast of the northeast Japan has a history of damage caused by big tsunamis such as Meiji Sanriku Tsunami in 1896, Showa Sanriku Tsunami in 1933 and Chilean Earthquake Tsunami in 1960. Moreover, recent research has found evidence that a giant tsunami called the Jyogan Earthquake Tsunami occurred in 869 (Minoura and Nakaya, 1991). It is estimated that the earthquake's magnitude was about M8, and that the tsunami penetrated 2 to $4 \mathrm{~km}$ inland (Sugawara et al. 2001; Satake et al. 2008). Similar wide inundation areas might have happened 1200 years ago. Considering that accumulation of stresses between the Pacific and the North American plates generates big earthquakes periodically, such big earthquakes and tsunami can occur every several hundreds to a thousand years. Based on such findings, the Headquarters for Earthquake Research Promotion plans to investigate the big earthquakes and tsunamis off the Pacific coasts. Unfortunately, such a major event happened before such scientific findings could be incorporated into practical policies, plans and actions.

\section{Conclusions}

Characteristics and damages vary between disasters. The most significant feature of the Great East Japan Earthquake and Tsunami is in its complexity. We should regard it as not a simple composite disaster but a giant composite disaster. The combination of an earthquake of M9.0 and a giant tsunami was unprecedented in Japan's recent history. Furthermore, the combination of these natural events and the nuclear accident makes this a disaster with serious and widespread damage.

Japan, and northeast Japan in particular, have for a long time been increasing the preparedness against earthquakes and tsunamis. Despite this, huge damage occurred. This indicates that the Great East Japan Earthquake and Tsunami was beyond past experiences and our expectation. This event suggests that we should not only implement disaster prevention based on improved scientific understanding, but also take into account the possibility of maximum potential hazards.

For the reconstruction of the heavily impacted areas, should people continue to live in the same areas in the future? This is an important question. Given the potential high risk levels in these areas, we need to examine the strategy for disaster prevention and recovery. In order to save lives in the face of a 1/1000 year tsunami, there are no ways other than quick evacuation and rescue. We should remember this concept clearly. At the same time, we can protect human lives and socioeconomic activities against more frequent and lower magnitude tsunamis by using a combination of hard and soft measures. An idea emerging in the discussion for reconstruction of the northeast Japan is division of living and working places. People should live in higher places, while they work on the coastal areas because low-lying coastal areas are still effective and important for ports, fishery ports and 
commercial activities. Therefore, coastal dykes, coastal forests and other facilities should be reconstructed so that they can protect the economically important coastal areas against using design criteria such as 1/200 or more frequent events. Although discussions are only starting, we need to reestablish flexible and disaster prevention systems with multilayered targets.

At the same time, Japan's society also should address the other problems which were recognized as sustainability issues for a long time before the earthquake and tsunami. They are how to address the aging society, climate change and nature friendly society in an integrated manner. The reconstruction is not merely the reconstruction of the former local societies. We should create new societies which are safer, more environmentally friendly and more vital. This is a real challenge for Japanese society.

The historical event and the resulting damage shocked all social sectors, including the research community. Recent findings of scientific research were not transferred to the improvement of the protection of nuclear power plants and other important facilities. This is a problem for the decision-making system of society. We realize that there were barriers among different fields to hamper information flows between disciplines. Single academic fields cannot resolve a real world problem. Rather, multi-disciplinary approaches are necessary to meet the challenges facing society. This has been recognized for a relatively long time, but we need to realize the importance of this notion and develop new mechanisms to promote multi-disciplinary cooperation. This is how academic society can contribute to the reconstruction of the Japanese society.

Immediately after the earthquake and tsunami occurred we received numerous emails, telephone calls and letters from friends in many countries. These are most encouraging to us. In addition, Dr Robert Dixon, Editor of Mitigation and Adaptation Strategies for Global Change, kindly offered an opportunity to present a timely report. We appreciate Prof. John Hay for his careful proof reading and correction of English of the draft. We hope that this paper assists many people to understand the situation that is ongoing in Japan.

Open Access This article is distributed under the terms of the Creative Commons Attribution Noncommercial License which permits any noncommercial use, distribution, and reproduction in any medium, provided the original author(s) and source are credited.

\section{References}

Disaster Countermeasures Office (2011a) About the 2011 Great East Japan Earthquake and Tsunami, http://www.kantei.go.jp/saigai/pdf/201104271700jisin.pdf (in Japanese)

Disaster Countermeasures Office (2011b) About the accident of Fukushima Nuclear Power Plants No.1 and 2 in 2011,166 p (in Japanese).

Earthquake Research Institute, The University of Tokyo (2011) Velocity profile and response stpectrum, http://outreach.eri.u-tokyo.ac.jp/eqvolc/201103_tohoku/\#lngprd (in Japanese)

Geographical Survey Institute (2011) About crustal movement in March, 2011, http://www.gsi.go.jp/WNEW/ PRESS-RELEASE/2011-goudou0408.htm (in Japanese)

Headquarters for Earthquake Research Promotion (2011): Evaluation of the 2011 off the Pacific Coast of Tohoku Earthquake, http://www.jishin.go.jp/main/chousa/11mar_sanriku-oki2/index.htm (in Japanese) 
Japan Meteological Agency (2011a) About the 2011 off the Pacific Coast of Tohoku Earthquake No.39, http://www.jma.go.jp/jma/press/1104/18a/kaisetsu201104181715.pdf (in Japanese)

Japan Meteological Agency (2011b) Distribution of estimated Japan's intensity of ground motion, http://www.seisvol.kishou.go.jp/eq/suikei/201103111446_288/201103111446_288_1.html (in Japanese)

Japan Weather Association (2011): Overview of the 2011 off the Pacific Coast of Tohoku Earthquake and tsunami (Second report), http:/www.jwa.or.jp/static/topics/20110422/tsunamigaiyou3.pdf (in Japanese)

Minoura, Nakaya (1991) Trances of tsunami preserved in inter-tidal lacustrine and marsh deposits: some examples from northeast Japan. J Geol 37(2):425-430

Satake K, Yukitani Y, Yamamoto S (2008) Numerical simulation on the AD 869 Jogan tsunami in Ishinomaki and Sendai Plains, Annual Report and Active Faults and Paleoearthquake Researches. AIST 8:71-89

Sugawara D, Minoura K, Imamura F (2001) Numerical reconstruction of sediment deposition caused by the AD 869 Jogan tsunami, Tsunami Engineering Research Report, 18, Disaster Control Research Center, Tohoku University, pp.1-10 (in Japanese).

Tohoku Power Co (2011) Report on analysis of the earthquake record and tsunami observed during the 2011 off the Pacific Coast of Tohoku Earthquake at Onagawa Nuclear Power Plant (in Japanese).

Tokyo Electric Power Co (2011) Press release about results of the survey on tsunami effects on Fukushima Nuclear Power Plants No.1 and 2, http://www.tepco.co.jp/cc/press/11040904-j.html (in Japanese) 